Available online at http://jddtonline.info REVIEW ARTICLE

\title{
FLOATING DRUG DELIVERY SYSTEM: A REVIEW
}

\author{
*Bharkatiya Meenakshi ${ }^{1}$, Kitawat Santosh ${ }^{2}$, Ojha Annapurna ${ }^{1}$ \\ ${ }^{1}$ B.N. Institute of Pharmaceutical Sciences, Udaipur. (Raj.), India \\ ${ }^{2}$ Geetanjali Institute of Pharmacy, Udaipur. (Raj.), India \\ *Corresponding Author's Email id: meenakshibharkatiya@rediffmail.com, Phone no: 09214363518
}

\begin{abstract}
The main goal of any drug delivery system is to achieve desired concentration of the drug in blood or tissue, which is therapeutically effective and non toxic for a prolonged period. Various attempts have been made to develop gastroretentive delivery systems such as high density system, swelling, floating system. The recent developments of FDDS including the physiological and formulation variables affecting gastric retention, approaches to design single-unit and multiple-unit floating systems, and their classification and formulation aspects are covered in detail. This review also summarizes the studies to evaluate the performance and application of floating systems, and applications of these systems. Gastric emptying is a complex process and makes in vivo performance of the drug delivery systems uncertain. In order to avoid this variability, efforts have been made to increase the retention time of the drug-delivery systems for more than 12 hours. The floating or hydrodynamically controlled drug delivery systems are useful in such application.
\end{abstract}

Key Words: Floating, gastrointestinal, gastro retentive system, evaluation.

\section{INTRODUCTION}

The oral route is considered as the most promising route of drug delivery. Effective oral drug delivery may depend upon the factors such as gastric emptying process, gastrointestinal transit time of dosage form, drug release from the dosage form and site of absorption of drugs ${ }^{\mathbf{1 , 2}}$. Floating multiparticulate are gastro-retentive drug delivery systems based on non-effervescent and effervescent approach. Hollow microspheres are in strict sense, spherical empty particles without core. These microspheres are characteristically free flowing powders consisting of proteins or synthetic polymers, ideally having a size less than 200 micrometer. $^{3}$

Gastroretentive systems can remain in the gastric region for several hours and hence significantly prolong the gastric residence time of drugs. Prolonged gastric retention improves bioavailability, reduces drug waste, and improves solubility for drugs that are less soluble in a high $\mathrm{pH}$ environment. ${ }^{4}$

It is a formulation of a drug with gel forming hydrocolloids meant to remain buoyant in the stomach contents. Drug dissolution and release from the dosage form retained in the stomach fluids occur at the $\mathrm{pH}$ of the stomach under fairly controlled conditions ${ }^{5}$.

\section{SUITABLE DRUG CANDIDATES FOR GASTRO RETENTION $^{6}$}

In general, appropriate candidates for gastroretentive dosage form are molecules that have poor colonic absorption but are characterized by better absorption properties at the upper parts of the GIT:

- Narrow absorption window in GI tract, e.g., riboflavin and levodopa
- Primarily absorbed from stomach and upper part of GI tract, e.g., calcium supplements, chlordiazepoxide and cinnarazine

- Drugs that act locally in the stomach, e.g., antacids and misoprostol

- Drugs that degrade in the colon, e.g., ranitidine $\mathrm{HCl}$ and metronidazole

- Drugs that disturb normal colonic bacteria, e.g., amoxicillin trihydrate

\section{CLASSIFICATION OF DRUG DELIVERY SYSTEM}

\section{A. Single Unit Floating Dosage Systems}

a) Effervescent Systems (Gas-generating Systems)

b) Non-effervescent Systems

\section{B. Multiple Unit Floating Dosage System}

a) Effervescent Systems (Gas-generating Systems)

b) Non-effervescent Systems

c) Hollow Microspheres

\section{Raft forming system}

\section{A. Single Unit Floating Dosage Systems}

Single unit dosage forms are easiest to develop but suffers from the risk of losing their effects too early due to their all or none emptying from the stomach and, thus they may cause high variability in bioavailability and local irritation due to large amount of drug delivered at a particular site of the gastro intestinal tract ${ }^{\mathrm{T}}$.

a) Effervescent Systems (Gas-generating Systems) 
These are matrix types of systems prepared with the help of swellable polymers such as methylcellulose and chitosan and various effervescent compounds, e.g. sodium bicarbonate, tartaric acid, and citric acid. They are formulated in such a way that when in contact with the acidic gastric contents, $\mathrm{CO} 2$ is liberated and gets entrapped in swollen hydrocolloids, which provides buoyancy to the dosage forms ${ }^{8}$.

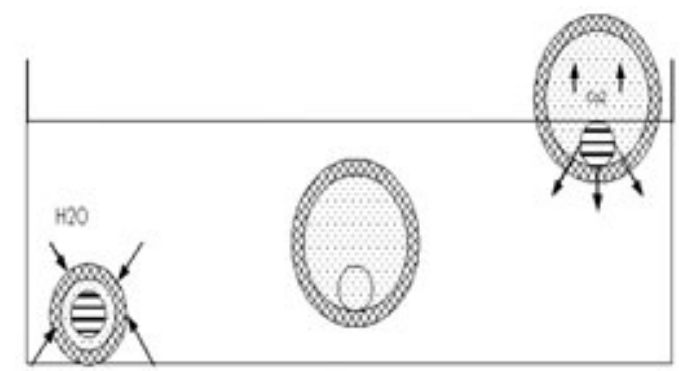

Figure 1: Working principle of effervescent floating drug delivery system

\section{b) Non-effervescent Systems}

Non-effervescent floating dosage forms use a gel forming or swellable cellulose type hydrocolloids, polysaccharides, and matrix forming polymers like polycarbonate, polyacrylate, polymethacrylate, and polystyrene. The formulation method includes a simple approach of thoroughly mixing the drug and the gelforming hydrocolloid. After oral administration this dosage form swells in contact with gastric fluids and attains a bulk density of $<1$. The air entrapped within the swollen matrix imparts buoyancy to the dosage form. The so formed swollen gel-like structure acts as a reservoir and allows sustained release of drug through the gelatinous mass. Excipients used most commonly in these systems include hydroxypropyl methyl cellulose (HPMC), polyacrylate polymers, polyvinyl acetate, Carbopol, agar, sodium alginate, calcium chloride, polyethylene oxide and polycarbonate?

\section{B. Multiple Unit Floating Dosage Systems}

Multiple unit dosage forms may be an attractive alternate since they have been shown to reduce inter and intra- subject variabilities in drug absorption as well as to lower the possibility of dose dumping. Various multiple unit floating systems have been developed in different forms, and using principles such as air compartment multiple unit system, hollow microspheres prepared by emulsion solvent diffusion method, beads prepared by emulsion gelation method. Use of effervescent and swellable polymer is another approach for preparing multiple unit FDDS ${ }^{\mathbf{1 0}}$.

\section{a) Effervescent Systems}

A multiple unit system comprises of calcium alginate core and calcium alginate/PVA membrane, both separated by an air compartment was prepared. In presence of water, the PVA leaches out and increases the membrane permeability, maintaining the integrity of the air compartment. Increase in molecular weight and concentration of PVA, resulted in enhancement of the floating properties of the system. Freeze- drying technique is also reported for the preparation of floating calcium alginate beads. Sodium alginate solution is (c) 2011, JDDT. All Rights Reserved added drop wise into the aqueous solution of calcium chloride, causing the instant gelation of the droplet surface, due to the formation of calcium alginate. The obtained beads are freeze- dried resulting in a porous structure, which aid in floating. The authors studied the behavior of radiolabeled floating beads and compared with nonfloating beads in human volunteers using gamma scintigraphy. Prolonged gastric residence time of more than $5.5 \mathrm{~h}$ was observed for floating beads. The nonfloating beads had a shorter residence time with a mean onset emptying time of $1 \mathrm{hr}^{\mathbf{1 1}}$.

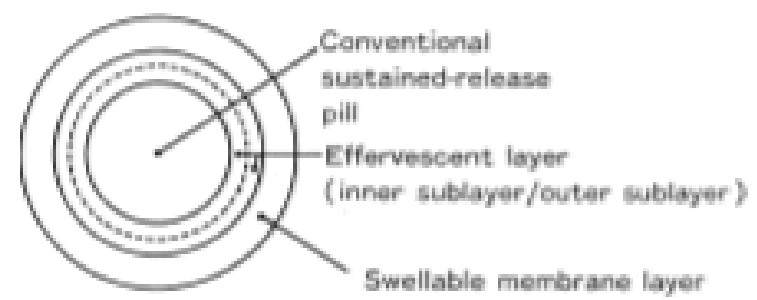

(a)

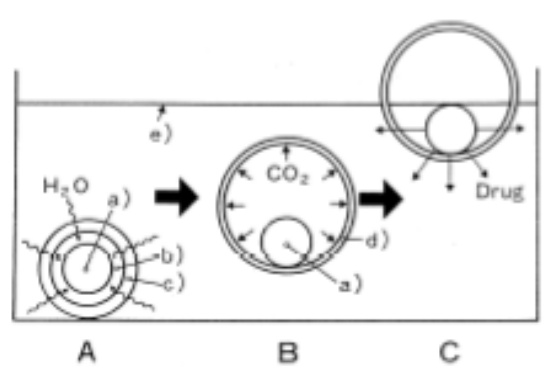

(b)

Figure 2: (a) A multi-unit oral floating dosage system. (b) Stages of floating mechanism: (A) penetration of water; (B) generation of $\mathrm{CO} 2$ and floating; (C) dissolution of drug. Key: (a)conventional SR pills; (b) effervescent layer; (c)swellable layer; (d) expanded swellable membrane layer; (e) surface of water in the beaker $\left(37^{0} \mathrm{C}\right)$.

\section{c) Non-effervescent Systems}

No much report was found in the literature on effervescent multiple unit systems, as compared to the effervescent systems. However, few workers have reported the possibility of developing such system containing indomethacin, using chitosan as the polymeric excipient. A multiple unit HBS containing indomethacin as a model drug prepared by extrusion process is reported. A mixture of drug, chitosan and acetic acid is extruded through needle, and the extrudate is cut and dried. Chitosan hydrates and floats in the acidic media, required drug release could be obtained by modifying the drug-polymer ratio ${ }^{12}$.

\section{d) Hollow Micro spheres}

Hollow microspheres loaded with drug in their outer polymer shelf were prepared by a novel emulsion solvent diffusion method. The ethanol/dichloromethane solution of the drug and an enteric acrylic polymer was poured into an agitated solution of Poly Vinyl Alcohol (PVA) that was thermally controlled at $400 \mathrm{C}$. The gas phase is generated in the dispersed polymer droplet by the evaporation of dichloromethane formed and internal cavity in the microsphere of the polymer with drug. The 
microballoon floated continuously over the surface of an than $12 \mathrm{hrs}^{\mathbf{1 3 , 1 4}}$ acidic dissolution media containing surfactant for more

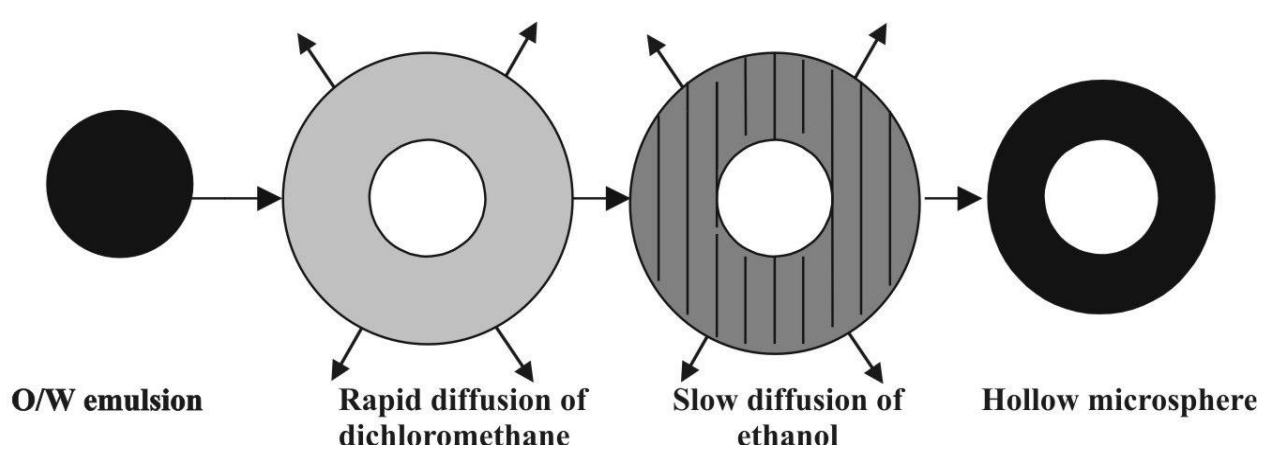

Figure 3: Formulation of floating microspheres

\section{Raft forming system}

Here, a gel-forming solution (e.g. Sodium alginate solution containing carbonates or bicarbonates) swells and forms a viscous cohesive gel containing entrapped $\mathrm{CO} 2$ bubbles on contact with gastric fluid. Formulations also typically contain antacids such as aluminium hydroxide or calcium carbonate to reduce gastric acidity. Because raft forming systems produce a layer on the top of gastric fluids, they are often used for gastrooesophageal reflux treatment ${ }^{15,16}$.

\section{MECHANISM OF FLOATING SYSTEMS}

Floating drug delivery systems (FDDS) have bulk density lesser than gastric fluids, so they remain buoyant in the stomach without affecting the gastric emptying rate for a prolonged period of time. While the system is floating on the gastric contents, the drug is released slowly at the desired rate from the system. However, besides a minimal gastric content needed to allow the proper achievement of the buoyancy retention principle, a minimal level of floating force $(F)$ is also required to keep the dosage form reliably buoyant on the surface of the meal. To measure the floating force kinetics, a novel apparatus for determination of resultant weight has been reported in the literature. The apparatus operates by measuring continuously the force equivalent to $\mathrm{F}$ (as a function of time) that is required to maintain the submerged object. This apparatus helps in optimizing FDDS with respect to stability and durability of floating forces produced in order to prevent the drawbacks of unforeseeable intragastric buoyancy capability variations ${ }^{17}$.

\section{ADVANTAGES OF FLOATING DRUG DELIVERY SYSTEMS}

Floating dosage systems form important technological drug delivery systems with gastric retentive behavior and offer several advantages in drug delivery. These advantages include:

1. FDDS can remain in the stomach for several hours and therefore prolong the gastric retention time of various $\operatorname{drugs}^{18}$.

2. FDDS are advantageous for drugs meant for local action in the stomach eg: Antacids

3. FDDS dosage forms are advantageous in case of vigorous intestinal movement and in diarrhea to keep the (C) 2011, JDDT. All Rights Reserved drug in floating condition in stomach to get a relatively better response.

4. FDDS improves patient compliance by decreasing dosing frequency ${ }^{19}$.

5. Bioavailability enhances despite first pass effect because fluctuations in plasma drug concentration are avoided; a desirable plasma drug concentration is maintained by continuous drug release ${ }^{20}$.

6. Acidic substance like aspirin causes irritation on the stomach wall when come in contact with it hence; HBS/FDDS formulations may be useful for the administration of aspirin and other similar drugs.

7. The FDDS are advantageous for drugs absorbed through the stomach eg: Ferrous salts, Antacids. Improved drug absorption, because of increased GRT and more time spent by the dosage form at its absorption site.

8. Site-specific drug delivery ${ }^{21}$.

\section{LIMITATIONS OF GASTRORETENTIVE DRUG DELIVERY SYSTEMS}

1. Drugs which are irritating the gastric mucosa are also not suitable.

2. The drug substances that are unstable in the acidic environment of the stomach are not suitable candidates to be incorporated in the systems.

3. Not suitable for drugs that have solubility or stability problem in GIT $^{22}$.

4. The drugs that are significantly absorbed through out gastrointestinal tract, which undergo significant first pass metabolism, are only desirable candidate ${ }^{\mathbf{2 3}}$.

5. The ability to float relies on the hydration state of the dosage form. In order to keep these tablets floating, intermittent administration of water is beneficial ${ }^{24}$.

\section{EVALUATION OF FLOATING DRUG DELIVERY SYSTEMS}

1. Determination of hardness of tablet:- Randomly sampled twenty tablets in each batch of formulations should be used for the determination of hardness with the help of Monsanto type hardness tester ${ }^{25}$. 
2. Determination of weight variation:- Twenty tablets selected at the random are weighed accurately and the average weight of the tablet is calculated. Then the deviation of individual weight from the average weight is calculated.

3. Determination of thickness of the tablet:- The individual crown to crown thickness of ten tablets is determined using slide calipers for each batch ${ }^{\mathbf{2 6}}$.

4. Floating lag time: It is the time taken by the tablet to emerge on to the surface of dissolution medium and is expressed in seconds or minutes ${ }^{27}$.

4. Measurement of Floating Capacity: - Three individual tablets are put in individual flask containing $400 \mathrm{ml}$ of $0.1(\mathrm{~N})$ HCL solutions. Then the time in minutes for each tablets to go from the bottom to the top of the flask (floating lag time) and the time for which tablets constantly float on the water surface (duration of floating) are measured. The sample mean and standard deviation are then calculated ${ }^{28}$.

5. Angle of repose:- The frictional forces in a loose powder or granules can be measured by angle of repose. This is the maximum angle possible between the surface of a pile of powder or granules and the horizontal plane.

The granules were allowed to flow through the funnel fixed to a stand at definite height (h). The angle of repose was then calculated by measuring the height and radius of the heap of granules formed ${ }^{29}$.

\section{REFERENCES}

1) Bhowmik D, Chiranjib B, Chandira M, Jayakar B, Sampath Kumar KP, Floating drug delivery system, Der Pharmacia Lettre, 2009, 1(2), 199-218.

2) Reddy L, Murthy R, Floating dosage systems in drug delivery, Crit Rev Ther Drug Carrier Syst, 2002, 19, 553-585.

3) Dhole A, Gaikwad P, Bankar V, Pawar S, Floating multiparticulate drug delivery system: A novel approach to gastric retention, International Journal of Pharmaceutical Sciences Review and Research, 2011, 6(2), 205-211.

4) Arora S, Ali J, Ahuja A, Khar RK, Baboota S, Floating drug delivery systems, AAPS Pharm Sci Tech, 2005, 6(3), 372390.

5) Nanjan, Sockan, Ganesh, Deecaraman, Formulation and evaluation of floating drug delivery system of ketoprofen, Journal of Pharmacy Research, 2011, 4(2), 424-428.

6) Garg R, Gupta GD, Progress in controlled gastro retentive delivery systems, Tropical Journal of Pharmaceutical Research, 2008, 7(3), 1055-1066.

7) Whitehead L, Collet JH, Fell JT, Sharma HL, Smith AM, Floating dosage forms: an in vivo study demonstrating prolonged gastric retention, Journal of Controlled Release, 1998, 55, 3-12.

8) Narang N, An updated review on floating drug delivery system, International Journal of Applied Pharmaceutics, 2011, $3(1), 1-7$.

9) Khan $\mathrm{AD}$, Bajpai M: Floating drug delivery system: An overview, International Journal of Pharm Tech Research, 2010, 2(4), 2498-2499.

10) Nasa P, Mahant S, Sharma D, Floating Systems: a novel approach towards gastroretentive drug delivery Systems, International Journal of Pharmacy and Pharmaceutical Sciences, 2010, 2(3), 1-7.

11) Iannuccelli V, Coppi G, Cameroin R, Air compartment multiple unit system for prolonged gastric residence. II. In vivo evaluation, International Journal of Pharmacy, 1998, 174, 55-62. $\tan \theta=\mathbf{h} / \mathbf{r}$

$\theta=\tan -1(h / r)$

$\boldsymbol{\theta}=$ angle of repose

$\mathbf{h}=$ height of the heap

$\mathbf{r}=$ radius of the heap

\section{Determination of In Vitro Dissolution Study}

The test for buoyancy and in vitro drug release studies are usually carried out in simulated gastric and intestinal fluids maintained at $37^{\circ} \mathrm{C}$. In practice, floating time is determined by using the USP dissolution apparatus containing $900 \mathrm{ml}$ of $0.1 \mathrm{HCl}$ as a testing medium maintained at $37^{\circ} \mathrm{C}$. The time required to float the HBS dosage form is noted as floating (or floatation) time ${ }^{\mathbf{3 0}}$.

\section{CONCLUSION}

Drug absorption in the gastrointestinal tract is a highly variable procedure and prolonging gastric retention of the dosage form extends the time for drug absorption. Drug absorption in the gastrointestinal tract is a highly variable process and prolonging gastric retention of the dosage form extends the time for drug absorption. Thus gastro retentive dosage forms provide an additional advantage for drugs that are absorbed primarily in the upper segments of gastrointestinal tract.

12) Hardenia SS, Jain A, Patel R, kaushal A, Floating drug delivery systems: A review, Asian Journal of Pharmacy and Life Science, 2011, 1(3), 284-293.

13) Borase CB, Floating systems for oral controlled release drug delivery, International Journal of Applied Pharmaceutics, 2012, 4(2), 1-13.

14) Bardonnet PL, Faivre V, Pugh WJ, Piffaretti JC, Falson F, Gastroretentive dosage forms: Overview and special case of Helicobacter pylori, Journal of Controlled Release, 2006, 1(111), 1-18.

15) Chordiya MA, Senthilkumaran K, Gangurde HH, Tamizharasi $\mathrm{S}$, Floating drug delivery system: a versatile approach for gastric retention, International Journal of Pharmaceutical Frontier Research, 2011, 1(3), 96-112.

16) Kawashima $Y$, Niwa $T$, Takeuchi $H$, Hino $T$, Ito $Y$, Preparation of multiple unit hollow microspheres (microballoons) with acrylic resins containing tranilast and their drug release characteristics (in vivo), Journal of Controlled Release, 1991, 16, 279- 290.

17) Garg S, Sharma S, Gastroretentive Drug Delivery System, Business Briefing Pharmatech, 2003, 160-166.

18) Kadam SM, Kadam SR, Patil US, Ratan GN, Jamkandi VG, Review on floating drug delivery system, International Journal of Research in Ayurveda \& Pharmacy, 2011, 2(6), 1752-1755.

19) Dixit N, Floating drug delivery system, Journal of Current Pharmaceutical Research, 2011, 7(1), 6-20.

20) Chandel A, Chauhan K, Parashar B, Kumar H, Arora S, Floating drug delivery systems, International Current Pharmaceutical Journal, 2012, 1(5), 110-118.

21) Babu VBM, Khar RK, In vitro and In vivo studies of sustained release floating dosage forms containing salbutamol sulphate, Pharmazie, 1990, 45, 268-270.

22) Mathur P, Saroha K, Syan N, Verma S, Nanda S, Valecha V, An overview on recent advancements and developments 
in gastroretentive buoyant drug delivery system, Pelagia Res Lib, 2011, 2(1), 161-169.

23) Mayavanhsi AV, Gajjar SS, Floating drug delivery systems to increase gastric retention of drugs, Research Journal Pharmaceutics and Technology, 2008, 1(4), 345-348.

24) Rouge N, Buri P, Doelkar E, Drug absorption site to the gastro intestinal tract and dosage form for site specific drug delivery, International Journal of Pharmaceutics, 1996, 136, 117-139.

25) Jain AK, Hatila U, A review on floating drug delivery system, International Journal of Pharmaceutical Studies and Research, 2011,2(3), 1-6.

26) Vidyadhara S, Rao PR, Prasad JA, Development and In-Vitro Kinetic of propanolol hydrochloride controlled release matrix tablets, The Indian Pharmacist, 2006, 66-70.
27) Nandigoti J, Shayeda, Floating drug delivery system, International Journal of Pharmaceutical Sciences and Nanotechnology, 2009, 2(3), 595-604.

28) Shoufeng L, Senshang L, Chein YW, Daggy BP, Mirchandani $\mathrm{HL}$, Statistical optimization of gastric floating system for oral controlled delivery of calcium, AAPS Pharm Sci Tech, 2001, $2,1-12$.

29) Sharma N, Agarwal D, Gupta MK, Khinchi MP, A comprehensive review on floating drug delivery system, International Journal of Research in Pharmaceutical and Biomedical Sciences, 2011, 2(2), 428-441.

30) Patil JM, Hirlekar RM, Gide PS, Kadam VJ, Trends in floating drug delivery system, Journal of Scientific and Industrial Research, 2006, 65, 11-21. 